\title{
FORMAÇÃO DE PROFESSORES NA EDUCAÇÃO INFANTIL: A EXPERIÊNCIA DE UM CURSO DE APERFEIÇOAMENTO/EXTENSÃO EM CASTANHAL-PA.
}

Osmar Chaves da Cruz ${ }^{1}$

\section{RESUMO}

O presente artigo versa sobre a temática da formação de professores na educação infantil, tomando como base para suas reflexões as experiências que foram vivenciados no Município de Castanhal-Pa a partir de um curso de aperfeiçoamento/extensão. Sendo assim, nossas reflexões e análises se desenvolveram a partir do seguinte objetivo: Analisar 0 "curso de aperfeiçoamento/extensão - currículo, planejamento e organização do trabalho pedagógico na educação infantil", ministrado pela UFPA em pareceria com o MEC; município de Castanhal-Pa e sua repercussão na atuação de gestores e coordenadores dos Centros Municipais de Educação Infantil (CMEl's). Para que fosse possível o alcance do objetivo proposto trabalhamos com a combinação da pesquisa bibliográfica com a pesquisa de campo, na modalidade estudo de caso. É importante destacar que este artigo é resultado da dissertação de mestrado com o mesmo título que fora submetida ao Programa de Pós-Graduação em Ciências da Educação da Faculdade Interamericana. Constatamos ao longo da pesquisa e neste artigo que a formação continuada dos professores da educação infantil por meio de cursos de extensão e aperfeiçoamento traz importante contribuições para a melhoria da qualidade do processo ensino-aprendizagem, bem como, orienta os docentes a assumirem um posicionamento crítico e de protagonista na organização do trabalho docente e pedagógico das instituições escolares.

Palavras-Chaves: Educação Infantil. Formação Continuada. Curso de Aperfeiçoamento/Extensão.

\section{1- INTRODUÇÃO}

Buscando investigar se o direito das crianças da educação infantil estão sendo garantidos ou negados, e ainda mais, como estão articuladas as formações para que estes direitos sejam efetivados na prática, adotamos como objetivo geral desse artigo: Analisar o "curso de aperfeiçoamento/extensão - currículo, planejamento e organização do trabalho pedagógico na educação infantil”, ministrado pela UFPA em pareceria com o MEC; o município de Castanhal-Pa e sua repercussão na atuação de gestores e coordenadores dos Centros Municipais de Educação Infantil (CMEl's).

\footnotetext{
1 Especialista em Educação na Secretaria Municipal de Educação de Castanhal; Professor de Educação Infantil (Creche) atuando como Coordenador da Educação Infantil na SEMED do Município de Santa Bárbara do Pará; Licenciatura Plena em Pedagogia pela UFPA; Licenciatura Plena em Sociologia pela UNIASSELVI; Licenciatura Plena em Ciências com habilitação em Biologia pela UEPA; Especialista em Gestão e Planejamento da Educação pela UFPA; Especialista em Administração e Gestão de Projetos Sociais - FAP; Especialista em Ludopedagogia e Literatura na Educação Infantil e Anos Inicias pela FAVENI e Mestre em Ciências da Educação pela FACULDADE INTERAMERICANA.
} 
Em termos metodológicos trabalhamos com a combinação da pesquisa bibliográfica e de campo, que teve no estudo de caso, os elementos necessários para compreender a realidade em questão. O referido curso ocorreu apenas nos anos de 2013 e 2015. Assim, a definição da amostra pelo curso ofertado em 2013 se justifica por ter sido o primeiro e do qual consegui ter acesso a alguns documentos, por meio da SEMED/Castanhal. Outrossim, depois do curso de 2013, os sujeitos tiveram mais tempo para colocar em prática os conhecimentos adquiridos na formação.

Diante disso, realizamos entrevista com 04 sujeitos, sendo duas coordenadoras pedagógicas e duas gestoras que se encontravam lotados, especificamente, nos CMEl's do município. A partir da coleta dos dados, trabalhamos com a técnica de análise de conteúdo para que fosse possível a interpretação dos dados, pois através dela, "podemos caminhar na descoberta do que está por traz dos conceitos manifestos, indo além das aparências do que está sendo comunicado" (GOMES, 2009, p. 84). Para Bardin (2016, p. 15), a análise de conteúdo é "um conjunto de instrumentos metodológicos cada vez mais sutis em constante aperfeiçoamento, que se aplicam a 'discursos' (conteúdos e continentes) extremamente diversificados".

Optamos por fazer algumas adaptações ao método utilizado por Bardin (2016), que propõe, primeiramente, que se faça a apresentação dos dados da pesquisa, posteriormente definir as categorias e, somente depois, fazer as análises e inferências. Todavia, irei apresentar os dados de acordo com as questões norteadoras e, logo em seguida, realizar as interpretações e inferências concomitantemente, para facilitar a compreensão dos leitores, fazendo com que 0 texto não fique sobrecarregado de quadros e tabelas. Assim, facilita-se a discussão sem ter que está voltando ao texto e retomando questões já apresentadas.

Como este artigo é apenas um recorte da dissertação apresenta ao Programa de Pós-Graduação em Ciências da Educação da Faculdade Interamericana, iremos apresentar somente os resultados obtidos e discutidos a luz dos referenciais teóricos que embasaram a pesquisa. Assim, apresentamos os dados da pesquisa e, em seguida, fazemos as discussões, a partir da análise de conteúdo. Constatamos por meio deste estudo a importância dos cursos de qualificação voltados para a prática pedagógica dos professores que atuam na educação infantil e que implicam também na qualidade do processo ensino-aprendizagem. 
2- $O$ CURSO DE EXTENSÃOIAPERFEIÇOAMENTO "CURRÍCULO, PLANEJAMENTO E ORGANIZAÇÃO DO TRABALHO PEDAGÓGICO NA EDUCAÇÃO INFANTIL"

Neste capítulo discutiremos os resultados das entrevistas realizadas com os sujeitos a respeito dos impactos, desafios e benefícios trazidos pelo curso de extensão/aperfeiçoamento "currículo e planejamento e organização do trabalho pedagógico na educação infantil”.

Como forma de preservar a identidade dos sujeitos, utilizamos as inicias de seus nomes, juntamente com a inicial de sua função ( $G$ - gestora e C-coordenadora) para que a pesquisa respeite os procedimentos éticos, mesmo que os entrevistados tenham assinado o termo de consentimento e autorizado a utilização de seus nomes no trabalho. Lembrando que todas as informantes estavam atuando na educação do município onde o curso foi ofertado (Castanhal/Pa), umas vindas de sala de aula, outras continuaram assumindo cargos de gestão e/ou coordenação pedagógica.

Tabela 1- o que foi o Curso de aperfeiçoamento/extensão - currículo, planejamento e organização do trabalho pedagógico na educação infantil?

\begin{tabular}{l|l}
\hline CATEGORIAS & \multicolumn{1}{c}{ SUJEITOS } \\
\hline & $\begin{array}{l}\text { S.R - C.C - É um curso de 180h [...] dividido em dois módulos [...] } \\
\text { formado por um conjunto de disciplinas. O MEC tinha um catálogo } \\
\text { de três cursos e a universidade optou por esse que era o "CURSO } \\
\text { DE APERFEIÇOAMENTO/EXTENSÃO - CURRICULO, }\end{array}$ \\
$\begin{array}{l}\text { Definição } \\
\text { curso do }\end{array}$ & $\begin{array}{l}\text { PLANEJAMENTO E ORGANIZAÇÃO DO TRABALHO } \\
\text { PEDAGÓGICO NA EDUCAÇÃO INFANTIL [...]ministrado de maio } \\
\text { a novembro de 2013 [...]formado de nove disciplinas [...]e eram } \\
\text { ministrados aos finais de semana, quinzenalmente, sexta e } \\
\text { sábado. As aulas eram presencias, professores todos aqui da } \\
\text { universidade, professores do ensino superior. }\end{array}$
\end{tabular}

Fonte: sujeito da pesquisa (Coordenadora do Curso)

A formação inicial nem sempre dá ao professor as condições necessárias para que ele consiga resolver os problemas do cotidiano da sala de aula, diante dos quais ele nem sempre sabe como reagir, sentindo-se incapaz e desestimulado. Assim, as formações continuadas devem ter como meta contribuir com os professores para a resolução dos problemas e acontecimentos da sala de aula.

O sucesso dos alunos se coloca como responsabilidade quase que total do professor. No entanto, é preciso dar-lhe condições básicas de trabalho, de formação, enfim, de aparatos que possam contribuir para que desenvolva a docência com 
maestria. Logo, pensar, analisar e discutir a formação de professores é essencial e carece de mais atenção.

De um catálogo de três cursos, sugeridos pelo MEC à Universidade Federal do Pará (UFPA), foi escolhido o "CURSO DE APERFEIÇOAMENTO/EXTENSÃO CURRÍCULO, PLANEJAMENTO E ORGANIZAÇÃO DO TRABALHO PEDAGÓGICO NA EDUCAÇÃO INFANTIL", para nortear as formações nos municípios que tivessem interesse em aderir à parceria. Formado por nove disciplinas e dividido em módulos, o curso acontecia quinzenalmente, nos dias de sexta e sábado, com aulas presenciais, ministradas por professores da própria UFPA.

Esse curso ocorreu entre os meses de maio e novembro de 2013, totalizando uma carga horária de 180h. De acordo com Teixeira e Araújo (2016), o MEC sugeriu três temáticas de curso de aperfeiçoamento: "Currículo, planejamento e organização do trabalho pedagógico na Educação Infantil"; "Campos de experiências e saberes e ação pedagógica na Educação Infantil" e "Educação Infantil, infâncias e arte", em que todos seriam financiados por ele (MEC), com apoio e acompanhamento da Coordenação Geral de Educação Infantil (COEDI), e em parceria com os municípios.

"O curso teve como público alvo, professores, coordenadores, diretores de creches e pré-escolas da rede pública de ensino, com o propósito de elevar o nível de conhecimento e aprimorar a prática pedagógica desses profissionais, segundo Teixeira e Araújo" (2016, p. 121). Diante do exposto consideramos ainda, a partir da fala dos sujeitos saber qual a importância do curso para suas práticas pedagógicas.

Tabela 2- importância do curso para a prática dos sujeitos

\begin{tabular}{|c|c|}
\hline SUB-CATEGORIA & SUJEITOS \\
\hline $\begin{array}{l}\text { Importância } \\
\text { curso }\end{array}$ & $\begin{array}{l}\text { A.R (G 01) - Ele foi um casamento da teoria com a prática, rico em } \\
\text { conhecimentos, na socialização de práticas, de material teórico, na } \\
\text { troca de conhecimento, vivências. Eu defino ele como rico em } \\
\text { conhecimentos teóricos e práticas pedagógicas. } \\
\text { R (G 02) - Ele foi um curso de grande valia, é um curso essencial } \\
\text { para que você conheça a educação infantil. Um curso essencial para } \\
\text { a formação do profissional. É essencial que todo profissional tenha } \\
\text { esse curso de extensão para poder se descobrir como profissional } \\
\text { da educação infantil. } \\
\text { M.H (C 01) - [...] Ele foi maravilhoso porque não foi só teoria, a } \\
\text { prática foi o essencial para nós. } \\
\text { G (C 02) - transformação nas nossas ações pedagógicas na } \\
\text { melhoria da qualidade do atendimento às crianças e assim } \\
\text { promovendo o desenvolvimento integral na educação infantil, é } \\
\text { assim que eu defino o curso. }\end{array}$ \\
\hline
\end{tabular}


A formação inicial que um professor recebe não dá conta de atender todas as demandas da realidade de uma sala de aula, porque os futuros docentes não vivenciam situações que ocorrem no ambiente educacional, não lhes são oportunizados momentos contínuos dessa vivência. Assim, quando se deparam com a realidade nua e crua, ficam apreensivos, nervosos, desnorteados, enfim. Não sabem como lidar com as situações, sentem-se despreparados e incapazes de enfrentar essa realidade, fato que faz com que alguns profissionais até desistam da carreira, porque não se encontrou nela.

Diante disso, a formação continuada, é uma "válvula de escape" para esses sujeitos, que precisam de ajuda para desenvolver sua docência, buscando nestes cursos, apoio e acompanhamento de seu trabalho, tirando suas dúvidas e melhorando sua prática. Para Pimenta e Libâneo (2006, p. 41),

\begin{abstract}
A formação inicial, por melhor que seja, não dá conta de colocar o professor à altura de responder, através de seu trabalho, às novas necessidades que Ihes são exigidas para melhorar a qualidade social da escolarização [...] pesquisas têm apontado para a importância do investimento no desenvolvimento profissional dos professores [...].
\end{abstract}

Neste sentido, acredita-se que a melhoria da qualidade da educação depende, em muitos aspectos, da formação do professor, que é o sujeito responsável por mediar as relações que se estabelecem entre os sujeitos (alunos), objeto do conhecimento e o próprio conhecimento.

Ao considerarmos, a formação inicial do professor como precária, apresentamos a necessidade urgente desse profissional se manter atualizado. E a melhor forma para essa atualização é a sua participação nos cursos de formação continuada, que podem ser oriundos de reuniões pedagógicas e trocas de experiência entre professores, assim como, promovidas pelo município, através da secretaria de educação.

$\mathrm{Na}$ fala dos sujeitos, temos evidenciado que o curso foi importante para o desenvolvimento e aperfeiçoamento de suas práticas pedagógicas, quando A.R (G 01) diz: "eu defino ele como rico em conhecimentos teóricos e práticas pedagógicas". Percebe-se aí a importância de a metodologia do curso sempre proporcionar essa relação da teoria com a prática, de buscar mostrar aos sujeitos a importância de realizar uma prática pedagógica embasada teoricamente, de tentar compreender o porquê que aquela metodologia deve ser trabalhada daquela forma e não de outra, 
como mais adiante R (G 02) vem afirmar: "As contribuições foram, na verdade essas, se tornaram essa práxis, essa teoria com essa prática, juntos".

Nesta última fala aparece o conceito de práxis, que para a gestora, seria a estreita relação entre a teoria e a prática. Entretanto, tem-se um outro conceito de práxis, defendido por Sanchez Vásquez, a partir das teorias de Marx, no artigo de Freitas (2018), no qual afirma que, a prática tem uma estreita relação com fatores externos que, aliados a um olhar mais denso daquilo que nos rodeia e construído a partir de "propostas" que culminam em alterações das circunstâncias, impulsiona mudanças.

Em suma, práxis estaria vinculado a "aliança entre a teoria e a prática; efetuada na realidade; traça objetivo proveniente da reflexão; cria finalidades; agir do homem, com ênfase ao aspecto coletivo; transformadora (FREITAS, 2018, p. 08). Logo, esse conceito de práxis, segundo Marx, é dinâmico, formador, reflexivo, que visa uma transformação, tanto no sujeito como na sociedade.

O curso também proporcionou a busca de uma definição identitária desses sujeitos, de se descobrir como profissional desse nível de ensino. Segundo a gestora $R$ (G 02), foi "[...] um curso essencial para a formação do profissional [...]. É essencial que todo profissional tenha esse curso de extensão para poder se descobrir como profissional da educação infantil". Para ela, um curso desse calibre é que seria como uma formação inicial para o professor, uma vez que the proporcionaria descobrir se era isso mesmo que queria, se tinha aptidão e perfil para desenvolver a docência, já que sua atuação também poderia se dar no ensino infantil.

Além disso, o curso possibilitou a troca de experiências entre os sujeitos, com a socialização de práticas oportunizadas pelo formato do curso, que abria espaço para esse tipo de atividade, de socialização de experiências exitosas, já que os participantes estavam atuando no ensino infantil.

De acordo com os dados coletados houve uma mudança significativa na prática dos professores, além da melhoria do atendimento às crianças. O primeiro sintoma positivo veio da definição do curso como essencial e indispensável ao profissional que trabalha na educação infantil, como se pode observar na fala de uma coordenadora, quando diz que o curso provocou uma "[...] transformação nas nossas ações pedagógicas, na melhoria da qualidade do atendimento às crianças e, assim, promovendo o desenvolvimento integral na educação infantil” G (C 02). Percebeu-se que, de acordo com a participação dos profissionais no curso, concomitantemente, já 
iam colocando em prática os conhecimentos aprendidos e percebendo a mudança, tanto na sua atuação prática quanto na melhoria do atendimento à criança.

Diante disso, pode-se afirmar que o curso proporcionou uma mudança significativa na prática pedagógica desses sujeitos, porque gerou benefícios riquíssimos para sua atuação na educação infantil, contribuiu para o desenvolvimento de uma prática comprometida com uma educação, que possibilita à criança ser sujeito do processo educacional, potencializando todos os aspectos da aprendizagem (social, cognitiva, afetiva, emotiva, etc.), enfim. Fez aflorar no CMEl'S do Proinfância, Castanhal/ $\mathrm{Pa}$, uma educação da/para criança, que levou em consideração seus múltiplos saberes, peculiaridades e heterogeneidade.

Sendo assim, buscamos conhecer também os impactos do curso sobre a prática dos professores:

Tabela 3 - impactos do curso nos CMEl's do município de Castanhal

\begin{tabular}{|c|c|}
\hline CATEGORIA & SUJEITOS \\
\hline Impa & $\begin{array}{l}\text { A.R (G 01) - a criança [...] tem desejos tem que ser respeitada na } \\
\text { sua individualidade; Organização (o portfólio, o planejamento, } \\
\text { sentar e planejar); estruturar o PPP; suporte teórico e suporte } \\
\text { prático; socializar práticas; dialogarmos em cima das nossas } \\
\text { práticas. } \\
\text { R (G 02) - outro olhar para o próprio desenvolvimento da criança; } \\
\text { a criança não é só um ser em miniatura, é um ser de direito; [...] } \\
\text { os trabalhos, as alturas (organização), por exemplo, das } \\
\text { atividades, o como lidar com a criança, a questão de rodinha; } \\
\text { outra visão de criança, outra visão de infância; práxis; outras } \\
\text { perspectivas; aperfeiçoadas essas experiências; se descobrir } \\
\text { como profissional da educação infantil. } \\
\text { M.H (C 01) - aperfeiçoar essa prática; fazer coisas novas; } \\
\text { experiências exitosas. } \\
\text { G (C 02) - transformação nas nossas ações pedagógicas; sujeitos } \\
\text { ativos, participativos nesse processo de formação de suas } \\
\text { funções de humanização (crianças); novas reflexões sobre } \\
\text { nossas praticas pedagógicas em relação ao currículo, } \\
\text { organização do tempo, espaço [...]; }\end{array}$ \\
\hline
\end{tabular}

Fonte: sujeitos da pesquisa

O curso trouxe inúmeras e significativas mudanças ao fazer dos sujeitos participantes, nos variados campos: em conhecimento de teóricos e documentos de referências do ensino infantil; em mudanças de conceitos, a partir do estudo de teóricos; no modo de organizar o trabalho pedagógico (registros, materiais, espaços, 
entre outros); de se relacionar e compreender as crianças; e principalmente, na atuação dos docentes, no modo destes desenvolverem seu trabalho na educação infantil, levando em consideração todas as peculiaridades que o ensino infantil apresenta.

Os impactos deste curso foram muito positivos para estes sujeitos, porque puderam organizar melhor suas instituições e currículo, no sentido de valorizar o protagonismo infantil, além de possibilitar uma reflexão, aperfeiçoamento e, até mesmo, mudanças em suas práticas, colocando em foco a criança, valorizando o cuidar e o educar, segundo a DCNEI (2010), assim como as interações e brincadeiras, segundo a BNCC (2017). Além do que, ficou entendido que as propostas pedagógicas de Educação Infantil devem respeitar os seguintes princípios,

\footnotetext{
Éticos: da autonomia, da responsabilidade, da solidariedade e do respeito ao bem comum, ao meio ambiente e às diferentes culturas, identidades e singularidades.

Políticos: dos direitos de cidadania, do exercício da criticidade e do respeito à ordem democrática.

Estéticos: da sensibilidade, da criatividade, da ludicidade e da liberdade de expressão nas diferentes manifestações artísticas e culturais (BRASIL, 2010, p. 16).
}

Neste sentido, tem-se proporcionado um ensino e uma aprendizagem que atenda as potencialidades da criança, em suas múltiplas dimensões, buscando o desenvolvimento de uma educação cidadã, que respeite a criança e a considere como presente, sujeito histórico, cultural, social e ativo, não a enxergando como futuro, o vir a ser, como a sociedade a define.

\section{1 - A Possibilidade de Conhecimentos de Documentos e Referências do Ensino Infantil}

Tabela 4 - benefícios do curso no conhecimento teórico e de documentos que norteiam a educação infantil

\begin{tabular}{|c|c|}
\hline SUB-CATEGORIA & SUJEITOS \\
\hline $\begin{array}{l}\text { Conhecimento de } \\
\text { documentos éricos } \\
\text { referenciais teóricos }\end{array}$ & $\begin{array}{l}\text { A.R (G 01) - [..] Vygotsky porque ele vai tratar da criança com } \\
\text { o meio, ele fala todo tempo que o meio ele é determinante, ele } \\
\text { fala da criança enquanto sujeito, fala do materialismo histórico, } \\
\text { da teoria histórico-cultural. O Wallon quando fala da questão } \\
\text { da afetividade, Karl Marx quando vem falar desse sujeito } \\
\text { histórico, vem definir essa criança como sujeito, colocar dentro } \\
\text { de uma sociedade e o Paulo Freire. } \\
\text { R (G 02) - Foi falado muito nas teorias de Vygotsky, Piaget, } \\
\text { Sonia Kramer, a gente estudou muito o Referencial Curricular }\end{array}$ \\
\hline
\end{tabular}


da educação infantil, foi quando vim ter mais uma afinidade com o documento[...];

M.H (C 01) - se trabalhou muito com Emília Ferrero e Vygotsky; G (C 02) - a gente viu Vygotsky e seus colaboradores que defendem a ideia de garantia, condições de crianças serem crianças, de viverem suas infâncias e [...] contudo, sem negar o papel de um adulto em especial dos professores no seu processo de humanização é [...] diante dessa base teórica que é a histórico-cultural.

Fonte: sujeitos da pesquisa

$\mathrm{Na}$ formação inicial (graduação e/ou ensino médio magistério), estudamos os principais teóricos que nos proporcionam compreender e assistir as crianças. Estudamos disciplinas (psicologia, psicogênese, entre outras), leis (Constituição Federal, LDB, DCNEI, RCNEI, BNCC, etc.), entre outros documentos norteadores do ensino infantil, que nos possibilitam um olhar mais atento à educação de crianças. Todavia, a carga horária dessas disciplinas é insuficiente para que estudemos mais a fundo essas teorias e leis.

Logo, essa formação preliminar se torna deficiente por não abranger todos os conhecimentos necessários para se exercer a docência. Diante disso, o aprofundamento dos estudos, nessas áreas, é de suma importância para quem quer ser um "bom professor".

Para Nóvoa (2018), cinco disposições são essenciais na definição dos professores, nos dias de hoje: o conhecimento, a cultura profissional, o tato pedagógico, o trabalho em equipe e o compromisso social. Essas disposições, devidamente contextualizadas, sintetizam o que os profissionais da educação precisam dominar para exercer sua profissão com qualidade.

A partir dos relatos, pode-se perceber que alguns entrevistados desconheciam e/ou não tinham tido acesso, ainda, aos documentos norteadores da educação: "a gente estudou muito o Referencial Curricular da Educação Infantil. Foi quando vim ter mais uma afinidade com o documento" $R$ (G 02). Esse documento norteia todo o trabalho na Educação Infantil, direciona e é referência para o trabalho, não só do professor, como da coordenação e gestão, haja vista que esses agentes também estão diretamente ligados ao processo educacional.

Dos seis sujeitos entrevistados, quatro deles frisaram que o suporte teórico do curso foi a teoria histórico-cultural de Vygotsky, além de outros autores como Wallon, Piaget, Emília Ferrero, Marx, Paulo Freire e Sonia Kramer, os quais vieram dá suporte e complemento aos estudos sobre a infância. 
Antigamente, pensava-se que as qualidades humanas se manifestavam à medida que as crianças cresciam, que esse processo era natural e que dependia apenas da maturação biológica, defendida por Piaget. Hoje, temos outra visão de desenvolvimento, que resulta das experiências que a criança vive, de sua atividade e de sua aprendizagem, enfim, da relação que ela estabelece com o meio e com os outros.

Essa teoria pressupõe a concepção de desenvolvimento humano como processo de humanização. Para ela, "não nascemos humanos, mas nos tornamos humanos em contato com os outros e com a cultura historicamente acumulada pelos homens" (SANTOS; LEÃO, 2018, p. 03). É por esse viés que as funções psicológicas superiores se formam, a partir de nossas relações sociais com a apropriação da cultura.

O compromisso político do professor fundamentado na abordagem histórico-
cultural é o de proporcionar a formação das qualidades humanas em suas
máximas potencialidades, constituindo indivíduos críticos e éticos. Educar
exige posicionamento político, escolhas, opções. É necessário que o/a
professor/a tenha claro do que quer desenvolver em seus alunos, que tipo de
aluno quer ajudar a formar e para qual sociedade, já que assim como o ato
de educar proporcionará a emancipação dos envolvidos no processo de
ensino-aprendizagem, poderá também manter o status quo na sociedade
(SANTOS; LEÃO, 2018, p. 10).

Nesse sentido, Vygotsky e demais estudiosos da teoria histórico-cultural entendem que o sujeito não nasce pronto, mas, constitui-se se como sujeito, em suas relações sociais, no bojo das quais serão formadas suas qualidades humanas.

O processo de humanização, que também podemos chamar de educação, se forma a partir das relações sociais que vamos tecendo, ao longo de nossa vida, com sujeitos mais experientes. É quando vamos nos apropriando e internalizando as funções psíquicas humanas, que contribuirão para a formação e desenvolvimento de nossa personalidade e inteligência.

Para Mello (2015), a apropriação de capacidades, habilidades e aptidões, presentes no mundo, por meio dos objetos culturais que circundam a criança, precisam ser variados e atrativos, cabendo a adultos ou parceiros mais experientes, provê-los.

Nesse sentido, a formação desse sujeito/criança ocorrerá a partir da apropriação do mundo da cultura, tendo o outro como responsável pela sua humanização e afirmação do ser criança como ativo, capaz e transformador, haja vista que suas características e personalidades humanas são construídas ao longo da vida 
e pela intermediação do outro e das experiências que vivenciam por influência do meio, das pessoas e das atividades que realizam.

Para Mello (2015), a inteligência da criança se dá a partir de experiências desafiadoras, quanto mais propusermos desafios às atividades, mais poderemos contribuir para aumentar nível de inteligência da criança. Mas a autora faz uma ressalva, no sentido da não extrapolação do nível destas propostas, haja vista, que podem acarretar problemas no desenvolvimento infantil.

Assim, o desenvolvimento infantil está condicionado a três elementos que determinam a formação e o desenvolvimento das qualidades humanas: "o acesso à cultura como fonte das qualidades humanas, criadas ao longo da história; a função mediadora das pessoas mais experientes e a atividade que a criança realiza" (MELLO, 2015, p. 05).

Nesse sentido buscamos conhecer as implicações do curso no trabalho pedagógico escolar.

Tabela 5 - implicações ao trabalho pedagógico a partir do curso

\begin{tabular}{l|l}
\hline SUB-CATEGORIA & \multicolumn{1}{c}{ SUJEITOS } \\
\hline & $\begin{array}{l}\text { A.R (G 01) - A maior influência que ele trouxe foi a questão de } \\
\text { organização. O curso me deu esse suporte ele vem da } \\
\text { importância desse trabalho, como ele deve ser organizado, o } \\
\text { portfólio, o planejamento, sentar e planejar. }\end{array}$ \\
$\begin{array}{l}\text { Organização } \\
\text { Trabalho }\end{array}$ & $\begin{array}{l}\text { R (G 02) - [...] os trabalhos, as alturas, por exemplo, das } \\
\text { atividades, o como lidar com a criança, a questão de rodinha, } \\
\text { Pedagógico }\end{array}$ \\
$\begin{array}{l}\text { esse material está à altura da criança? De que serve uma letra } \\
\text { numa sala? Então, toda essa percepção a gente foi começando } \\
\text { a descobrir a partir dos conhecimentos que a gente estava } \\
\text { adquirindo no curso, então, houve uma mudança total, até } \\
\text { mesmo no próprio ambiente escolar, com tratar, como ser [...]. }\end{array}$
\end{tabular}

Fonte: sujeitos da pesquisa

As contribuições do curso para a organização do trabalho pedagógico, também foi um dos pontos importantes levantados e discutidos durante o curso, sendo um dos princípios básicos para o desenvolvimento das atividades pedagógicas. "A maior influência que ele trouxe foi a questão de organização". (A.R - G 01).

O curso me deu esse suporte, ele vem dá importância desse trabalho, como ele deve ser organizado, o portfólio, o planejamento, sentar e planejar" A.R (G 01). "[...] os trabalhos, as alturas, por exemplo, das atividades, o como lidar com a criança, a questão de rodinha, esse material está à altura da criança? De que serve uma letra numa sala? Então, toda essa percepção a gente foi começando a descobrir, a partir 
dos conhecimentos que a gente estava adquirindo no curso, então, houve uma mudança total, até mesmo no próprio ambiente escolar, como tratar, como ser [...]" R (G 02).

O curso oportunizou contribuições indispensáveis aos sujeitos orientando-os a como organizar os materiais, deixando-os ao alcance da criança para que ela toque; manuseie; orientando a forma de registrar o desenvolvimento dos alunos; o modo de organizar as atividades; levando em consideração a faixa etária e a singularidade de cada criança, assim como no modo de dialogar com ela, de ouvi-la, dar atenção e respeitar suas vontades.

A organização do tempo da atividade, os conteúdos, objetivos, metodologias, as estratégias de intervenção e avaliação são indispensáveis a todo processo educativo. No entanto, na educação, esse planejamento pedagógico assume uma importância crucial, ao mesmo tempo que deve ser flexível e estar sujeito a modificações. Como para a teria histórico-cultural a criança deve ser a protagonista do processo de aprendizagem, o professor precisa levar em consideração e valorizar os desejos, anseios e curiosidades da criança, segundo (SANTOS; LEÃO, 2018).

A forma como o ambiente está organizado também é um fator preponderante a se considerar no ensino infantil, pois deve-se buscar sempre o desenvolvimento das máximas qualidades humanas nas crianças, para sua constituição subjetiva, devendo contemplar a ludicidade, fortalecer a autonomia e a proporcionar a segurança dessas crianças. Um ambiente intencionalmente organizado propicia à criança o contato com diversificadas vivências e culturas, aí está a grande importância do adulto, especificamente do professor no processo de desenvolvimento da criança.

Santos e Leão (2018), afirmam que o ambiente deve auxiliar o professor na mediação da criança com a cultura, contemplando suas vivências, necessidades e as redimensionando, quando necessário. Já que nosso conceito de criança parte da teoria histórico-cultural, na qual ela assume papel ativo, dessa forma, a prática pedagógica deve conceber a sua realidade, mas não deve se limitar a ela.

\section{3- CONSIDERAÇÕES FINAIS}

A pesquisa analisou o "curso de aperfeiçoamento/extensão - currículo, planejamento e organização do trabalho pedagógico na educação infantil” e sua repercussão na atuação de gestores e coordenadores dos CMEl's do município de 
Castanhal, assim como perceber quais, os impactos e mudanças provocados pelo mesmo no ensino infantil do município.

A partir das discussões teóricas e das falas das entrevistadas constatamos que a formação inicial não está dando conta de atender em termos formativos as demandas que o trabalho pedagógico escolar na educação infantil exige. Nesse sentido, consideramos que a partir dos pressupostos da sociologia da infância e da teoria histórico-cultural, o trabalho escolar, em termos pedagógicos, deve ser dinâmico, lúdico, mas acima de tudo crítico, pois, tais correntes de pensamento concebem a criança como ser de direitos; agente ativa e transformadora das relações sociais; sujeito construtor de seu próprio conhecimento, desmistificando a imagem que tínhamos de uma criança passiva, que dependia em tudo de atenção do adulto apenas expectadora do processo, sendo vista pelo olhar do adulto.

Os dados coletados no decurso da pesquisa, revelaram a importância que o curso teve para a melhoria da prática pedagógica dos sujeitos que tiveram a oportunidade de participar e, que, o município ainda não tinha tido um curso tão rico em conhecimentos teóricos e práticos que valorizasse a infância e enfatizasse a importância de se conhecer a fundo as leis, teóricos e práticas exitosas que olhasse a criança a partir de sua perspectiva.

O curso, além de propiciar esse aprofundamento teórico, possibilitou que os sujeitos da pesquisa chamaram de "casamento", dessa união da teoria com a prática, porque ao mesmo tempo que iam conhecendo e compreendendo as teorias, iam aplicando em suas práticas pedagógicas, ou seja, já faziam essa materialização da teoria, na prática. Isso possibilitou ao curso uma referência muito boa, haja vista que ao mesmo tempo que discutiam uma prática inovadora na perspectiva da criança, aplicava em sala e já tinha o retorno dessa experiência no próximo encontro.

Em síntese consideramos que trabalhar formação a partir da prática dos sujeitos que estão diretamente ligados ao espaço escolar é imprescindível para que se sintam valorizados e suas angustias e dificuldades sejam enfrentadas e superadas de forma conjunta, uma vez que ainda se percebe muito nas escolas a falta de companheirismo e ajuda mútua entre professores, coordenadores e gestão. Em suma, precisamos buscar modelos de organização que venham provocar uma ruptura na forma de organização desses profissionais, onde ainda está havendo uma ausência de colaboração desses nos espaços escolares, afetando negativamente no desenvolvimento de seu trabalho pedagógico escolar. 


\section{REFERÊNCIAS}

BARDIN, Laurence. Análise de Conteúdo. Portugal: Edições 70, 1977.

BRASIL. Ministério da Educação e do Desporto. Secretaria de Educação Fundamental. Referencial curricular nacional para a educação infantil / Ministério da Educação e do Desporto, Secretaria de Educação Fundamental. - Brasília: MEC/SEF, 1998.

BRASIL. Ministério da Educação. Base Nacional Comum Curricular: Educação é a base. Versão final. Brasília: MEC, 2017.

BRASIL. Ministério da Educação. Secretaria de Educação Básica. Diretrizes Curriculares Nacionais para a Educação Infantil /Secretaria de Educação Básica. - Brasília: MEC, SEB, 2010.

FREITAS, Adenisia Alves de. O homem e a história na filosofia da práxis de Adolfo Sánchez Vázquez. Artigo produzido a partir da comunicação apresentada no Simpósio Temático no I Congresso de História e Literatura: "Tempo e Narrativa" na Unidade de Jussara (UEG) - Goiás-GO, [. Disponível em: < seer.ufms.br/index.php/fatver/article/download/1296/822>. Acesso em: 23 de set. de 2018.

GOMES, Romeu. Análise e interpretação de dados de pesquisa qualitativa. In: DESLANDES, Suely Ferreira. Pesquisa social: teoria, método e criatividade. Suely Ferreira Deslandes; Romeu Gomes; Maria Cecília de Souza Minayo (Organizadora). 28. Ed - Petrópolis, RJ: Vozes, 2009.

MELLO, Suely Amaral. Contribuições da teoria histórico-cultural para a educação da pequena infância. Revista Cadernos de Educação, n. ${ }^{\circ}$ 50•2015•ISSN: 2178-079X $2015 . \quad$ Disponível em: <https://periodicos.ufpel.edu.br/ojs2/index.php/caduc/article/view/5825>. Acesso em: 05 de set. de 2018.

NÓVOA, António. Para uma formação de professores construída dentro da profissão. Universidad de Lisboa. Facultad de Psicología y Ciencias de la Educación. Lisboa, Portugal, 2018. Disponível em: < http://www.revistaeducacion.educacion.es/re350/re350_09por.pdf>. Acesso em: 10 de set. de 2018.

PIMENTA, Selma Garrido; LIBÂENO, José Carlos. Formação de profissionais da educação: Visão crítica e perspectiva de mudança. In: PIMENTA, Selma Garrido (Org.). Pedagogia e pedagogos: caminhos e perspectivas. São Paulo: Cortez, 2006.

SANTOS, Larissa Andrade dos; LEÃO, Lísley Monteiro. A TEORIA HISTÓRICOCULTURAL E A EDUCAÇÃO DE CRIANÇAS DE 0 A 5 ANOS DE IDADE. II Congresso Nacional de Educação (CONEDU). Disponível em: <http://www.editorarealize.com.br/revistas/conedu/trabalhos/TRABALHO_EV045_M D1_SA17_ID2603_08062015120742.pdf.>. Acesso em: 25 de set. de 2018. 
TEIXEIRA, Sônia Regina dos Santos; ARAUJO, Ana Paula Melo de. Contribuições da teoria histórico-cultural para a universalização da pré-escola no Brasil. Textura, Canoas. v. 18 n.36, p.111-132. jan./abr. 2016. Disponível em: < http://www.periodicos.ulbra.br/index.php/txra/article/view/1748>. Acesso em: 14 de ago. de 2018. 